\title{
NEUTRON-PHYSICAL CHARACTERISTICS OF A SYSTEM OF QUASI-INFINITE DEPLETED URANIUM BLANKET - PARTICLE ACCELERATOR. MONTE CARLO SIMULATION
}

\author{
O.V. Bukhal', K.V.Husak', I.V.Zhuk', V.A. Voronko', V.V.Sotnikov', A.A. Zhadan', \\ A.A. Baldin ${ }^{3}$, S.I. Tyutyunnikov \\ ${ }^{1}$ State Scientific Institution "The Joint Institute for Power and Nuclear Research - Sosny" \\ NAS of Belarus, Minsk, Belarus; \\ ${ }^{2}$ National Science Center “Kharkov Institute of Physics and Technology”, Kharkiv, Ukraine; \\ ${ }^{3}$ Joint Institute for Nuclear Research, Dubna, Russia \\ E-mail: o.bukhal@gmail.com
}

Simulation of a quasi-infinite uranium target irradiated by $1 \mathrm{GeV}$ proton and deuteron particles with the help of FLUKA simulation package was carried out. Neutron spectra and neutron flux in a target volume were obtained. ${ }^{235} \mathrm{U}(\mathrm{n}, \mathrm{f}),{ }^{238} \mathrm{U}(\mathrm{n}, \mathrm{f}),{ }^{238} \mathrm{U}(\mathrm{n}, \mathrm{g})$ reaction rates in a target were determined. Beam particle power multiplication were calculated.

PACS: 29.27.Fh, 29.40.Wk, 29.90.+r

\section{INTRODUCTION}

An interest on study of the physical properties of ADS systems, in which a deeply subcritical active core is irradiated by relativistic deuteron or proton beams has growth in recent years. It is explained by the necessity of long lived radioactive waste management. Basic physical requirement for successful transmutation of such waste is highly intensive field of neutrons. High transmutation rates can be achieved by combination of high neutron intensity, proper neutron energy and reaction cross-section [1]. ADS systems are an ideal source of spallation neutron to transmute radioactive waste with simultaneous producing energy. Such a system is called Relativistic Nuclear Technology (RNT) [2].

The main features of RNT are a deep subcritical core made of natural uranium or thorium and energy of beams of accelerated projectiles increased up to $10 \mathrm{GeV}$. In such facilities with a minimal neutron leakage, a maximally hard neutron spectrum will serve for nuclear energy production and effective transmutation of spent nuclear fuel and long-lived radioactive waste [3].

An international collaboration "Energy plus Transmutation" established in the Laboratory of High Energy Physics of JINR (Dubna) is an international project for the study of spallation reactions, neutron production and transport and the transmutation of fission products and higher actinides by spallation neutrons as well as definition of optimal energy of incident beam for transmutation RAW and energy production.

Since 1997 the researchers of the Experimental Nuclear Physics Research and Expert Analyses of Radioactive Materials Laboratory of the SSI "The Joint Institute for Power and Nuclear Research - Sosny" NAS of Belarus have been taking part in the experiments on irradiation of a number of target systems of different geometries and composition with relativistic particles. The mass of investigated uranium targets differed from $206.4 \mathrm{~kg}$ ("Energy plus transmutation" setup) [4] to $512 \mathrm{~kg}$ (Quinta setup) [5]. Latter represents a central region of the quasi-infinite (with negligible neutron leakage) uranium spallation target but neutron leakage of Quinta setup is too large [6]. To confirm RNT we need to carried out the experiment with the big uranium target with the more amount of uranium and first we need to make the simulation as a part of preparation before the real experiments.

In this work the simulation of a quasi-infinite target which is called as a Big URANium target (short name Buran) was carried out. The total number of ${ }^{238} \mathrm{U},{ }^{235} \mathrm{U}$ fission reactions in a volume of target irradiated by proton and deuteron with $1 \mathrm{GeV}$ energy are obtained. Beam particle power multiplication is estimated.

Schematic drawing of Buran setup is presented on Fig. 1.

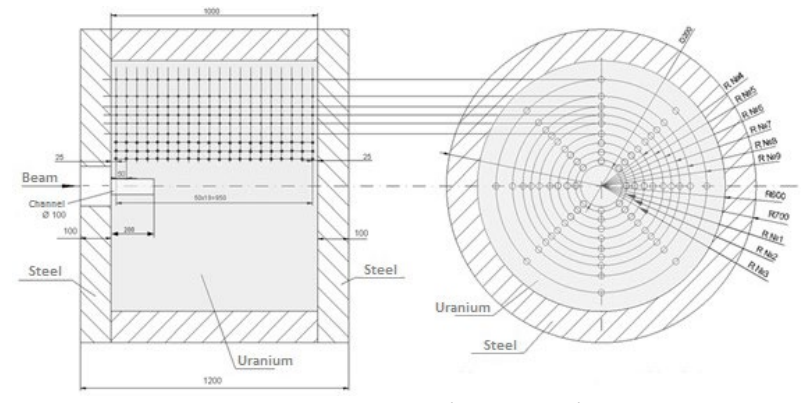

Fig. 1. Buran setup schematic drawing

\section{EXPERIMENT AND METHODS}

The BURAN setup can be considered as homogeneous and symmetrical, it would be useless to mark and perform calculations in all 1440 measuring points presented on Fig. 1. The simulation in this work was done on simplify designed setup presented on Fig. 2.
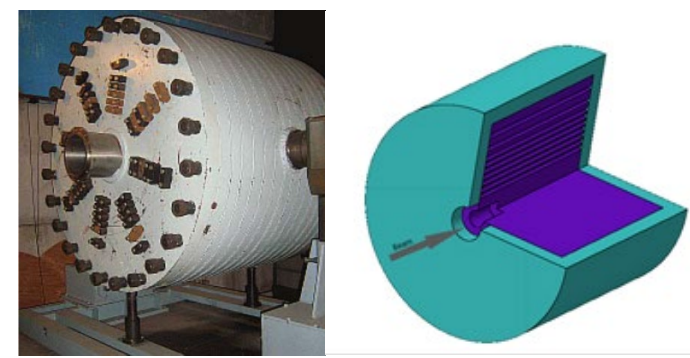

Fig. 2. Buran setup picture and simulation geometry

For the purpose of this calculation only set of channels was chosen. Buran setup is a huge cylinder made from depleted uranium with longitudinal distance of 1000 and $1200 \mathrm{~mm}$ in diameter. The cylinder is sur- 
rounded by $100 \mathrm{~mm}$ steel covering. The total mass of uranium in the target assembly is about 21 tones.

In this work the FLUKA code was used to perform all the simulations. FLUKA $[7,8]$ is a fully integrated particle physics Monte Carlo simulation package. FLUKA is a general purpose tool for calculations of particle transport and interactions with matter.

Simulation of Buran setup irradiated by $1 \mathrm{GeV}$ proton and deuteron particles was carried out. Obtained results were used to calculate a beam particle power multiplication.

The beam particle multiplication was calculated by the following expression (1) as was done in [6].

$$
G=\left(E_{p}+n_{f} \cdot E_{f}\right) / E_{p},
$$

where $E_{p}$ is the accelerated particle energy $(\mathrm{GeV}) ; n_{f}$ is the uranium fission numbers in the uranium assembly per one accelerated particle; $E_{f}$ is the fission energy which is equal to $0.197 \mathrm{GeV}$.

\section{RESULTS AND DISCUSSION}

The neutron spectra in a target were obtained and presented below. There is neutron flux on the surface of a target and a flux of neutron between uranium target and steel cover on Fig. 3 (incident particle - proton) and Fig. 4 (incident particle - deuteron).

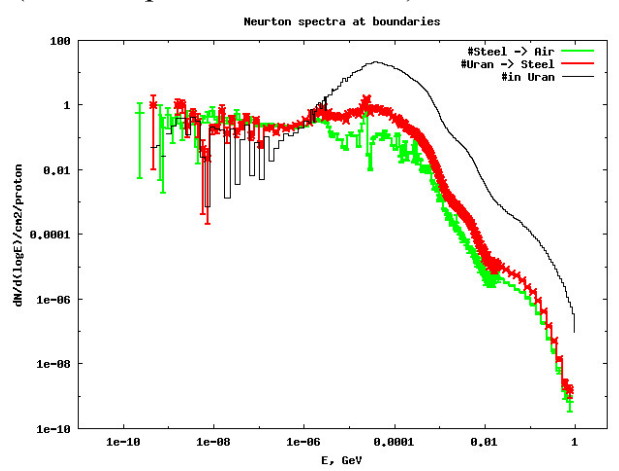

Fig. 3. Neutron spectra at boundaries

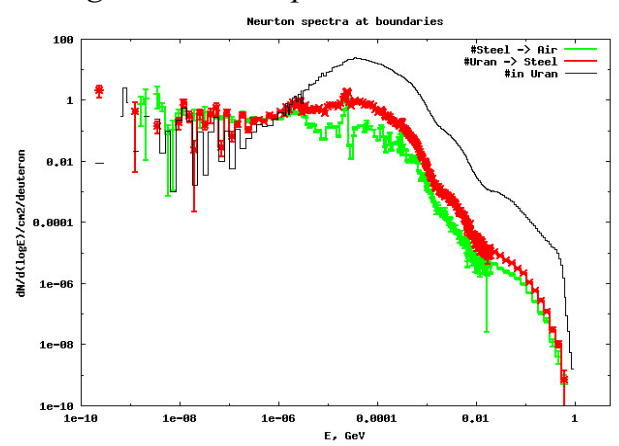

Fig. 4. Neutron spectra at boundaries

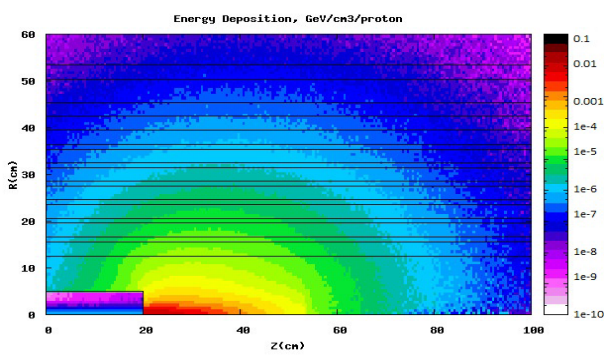

Fig. 5. Energy distribution in a target

Neutron flux on the surface generated by deuteron to neutron flux generated by proton is 1.16 times greater at the same projectile particle energy.
Energy distribution in a target irradiated by proton is presented on Fig. 5.

Energy distribution in a target irradiated by deuteron differs slightly from one irradiated by proton.

Energy distribution inside and around the target is presented on Fig. 6

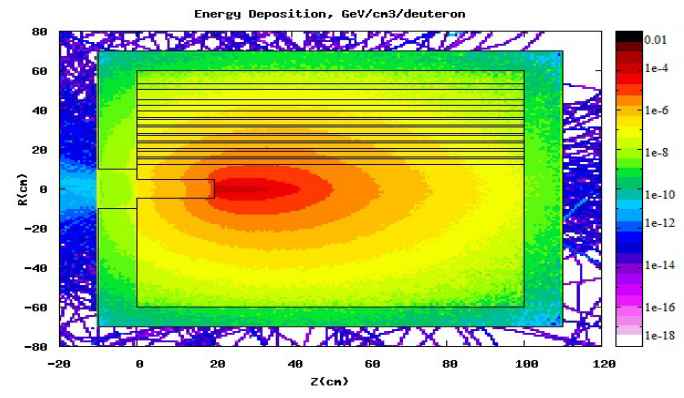

Fig. 6. Energy distribution in a target and around

Energy release outside Buran setup is converge to zero but it is clear visible there is a black flow of secondaries through the beam entering window.

Neutron flux longitudinal distributions for proton and deuteron projectiles are presented on Figs. 7 and 8 correspondingly.

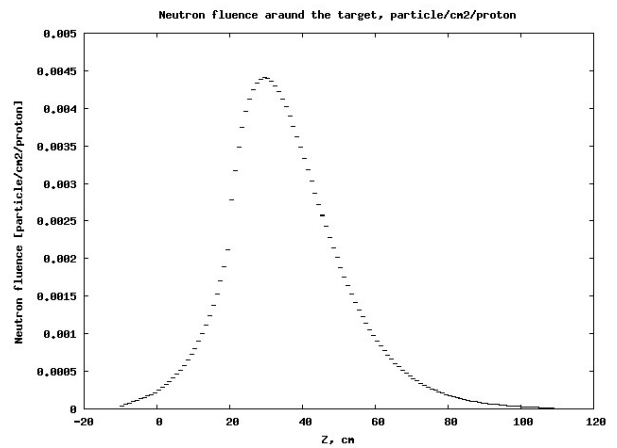

Fig. 7. Neutron flux, proton projectile

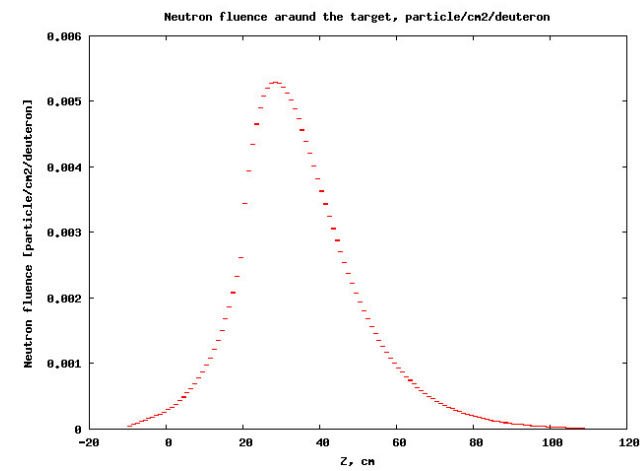

Fig. 8. Neutron flux, deuteron projectile

Maximum of neutrons is located on $\sim 28 \mathrm{~cm} \mathrm{Z}$ axis in both cases and converge to zero outside the target. Practically zero outside the target means all particles undergo interaction inside the target.

The neutron spectra in channels for experimental samples placement are presented below on Figs. 8-11. For clear readability there are only neutron spectra of four channels. Fluence in channels shows the decreasing of generated neutron number to the target edges. 


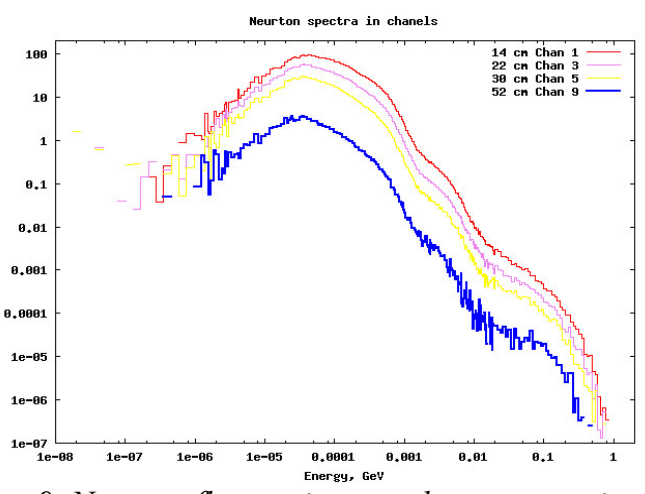

Fig. 9. Neutron fluence in cannel, proton projectile

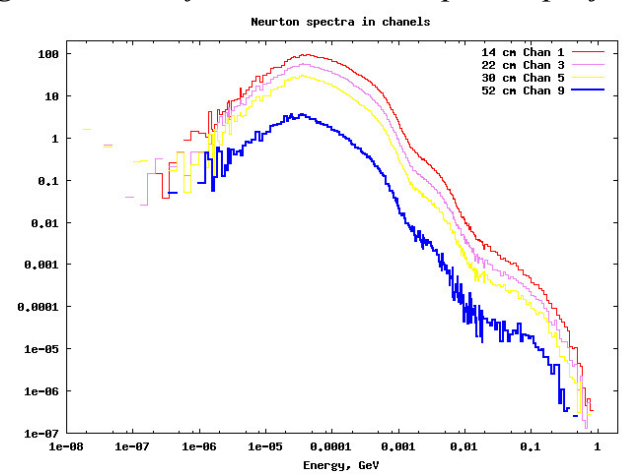

Fig. 10. Neutron fluence in channel, deuteron projectile

The energy and angle integrated length-averaged fluence of neutron in channels are presented on Fig. 9.

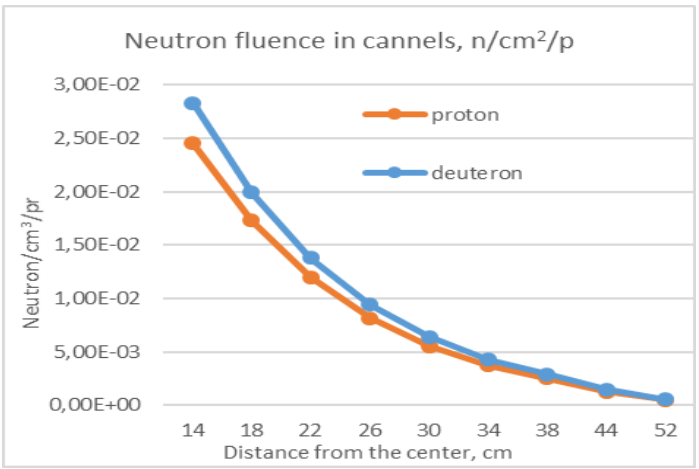

Fig. 11. Neutron fluence in channels

The flux in radial direction is decreased and converged to zero.

Using the obtained data we have got the total number of ${ }^{235} \mathrm{U}(\mathrm{n}, \mathrm{f}),{ }^{238} \mathrm{U}(\mathrm{n}, \mathrm{f}),{ }^{238} \mathrm{U}(\mathrm{n}, \mathrm{g})$ reactions occurred in a target. The proper cross-section data for neutron energy up to $20 \mathrm{MeV}$ were token from FLUKA file there are 260 grouped cross-section data. The crosssections above $20 \mathrm{MeV}$ were retrieved from ENDF database by A. Patapenka [4]. Beam power multiplication was calculated with the help of formula (1). Total number of ${ }^{235} \mathrm{U}(\mathrm{n}, \mathrm{f}),{ }^{238} \mathrm{U}(\mathrm{n}, \mathrm{f}),{ }^{238} \mathrm{U}(\mathrm{n}, \mathrm{g})$ reactions and beam power multiplication are presented in Table. The total number of calculated reactions is increased in $\sim 1.14$ times for deuteron projectiles, beam power generation in $\sim 1.12$ times and is about 4 . Such results are in a good agreement with the results obtained with the MCNPX simulation in [9].

Thus, simulation of Buran setup irradiated by proton and deuteron particles with the energy of 1 is carried out. Neutron spectra and neutron flux in a target volume are obtained and under deuteron irradiation is bigger in 1.16 times.

\section{Total number of ${ }^{235} U(n, f),{ }^{238} U(n, f),{ }^{238} U(n, g)$ \\ reactions and beam power multiplication}

\begin{tabular}{|c|c|c|c|c|}
\hline \multirow{2}{*}{$\begin{array}{l}\text { Projec- } \\
\text { tiles, } \\
\text { energy }\end{array}$} & \multicolumn{3}{|c|}{$\begin{array}{c}\text { Total number of reaction } \\
\text { in Buran target, } 1 / \text { projectiles }\end{array}$} & \multirow{2}{*}{$\begin{array}{l}\text { Power } \\
\text { multi- } \\
\text { plica- } \\
\text { tion }\end{array}$} \\
\hline & ${ }^{235} \mathrm{U}(\mathrm{n}, \mathrm{f})$ & ${ }^{238} \mathrm{U}(\mathrm{n}, \mathrm{f})$ & ${ }^{238} \mathrm{U}(\mathrm{n}, \mathrm{g})$ & \\
\hline $\begin{array}{l}\text { Proton, } \\
1 \mathrm{GeV}\end{array}$ & $1.26 \pm 0.06$ & $12.25 \pm 0,57$ & $52.23 \pm 2.43$ & 3.66 \\
\hline $\begin{array}{c}\text { Deuteron, } \\
1 \mathrm{GeV}\end{array}$ & $1.44 \pm 0.08$ & $14.31 \pm 0.75$ & $59.69 \pm 3.14$ & 4.10 \\
\hline
\end{tabular}

Neutron fluence in the last ninth channel that located $8 \mathrm{~cm}$ to the target edge and $52 \mathrm{~cm}$ from the central axis is only $2 \%$ of neutron fluence in the first channel that located $14 \mathrm{~cm}$ from the center for proton and deuteron projectiles.

Total number of ${ }^{235} \mathrm{U}(\mathrm{n}, \mathrm{f}),{ }^{238} \mathrm{U}(\mathrm{n}, \mathrm{f}),{ }^{238} \mathrm{U}(\mathrm{n}, \mathrm{g})$ reactions and beam power multiplication are calculated.

\section{REFERENCES}

1. J. Adam et al. Measurement of the high energy neutron flux on the surface of the natural uranium target assembly QUINTA irradiated by deuterons of 4 and $8 \mathrm{GeV}$ energy // Physics Procedia. 2015, v. 80, p. 94-97.

2. A.A. Baldin et al. Nuclear relativistic technologies (NRT) for energy production and utilization of spent nuclear fuel (SNF). The results of the first experiments on the physical substantiation of NRT // Physics of Particles and Nuclei Letters. 2011, v. 8, p. 1007-1023.

3. L. Zavorka et al. Validation of Monte Carlo simulation of neutron production in a spallation experiment // Annals of Nuclear Energy. 2015.

4. A. Potapenko et al. Studies on fission of $\mathrm{U}$ and $\mathrm{Pb}$ in spallation neutron field of "Energy plus transmutation" setup // XVIII International Baldin Seminar on High Energy Physics Problem: Proceeding of International Seminar, 5. Dubna, 10-15 Sept. 2008 / JINR, Dubna; editor: A.N. Sisakyan. 2009, v. 1, p. 240-249.

5. K. Husak et al. Recent results of the study of ADS with $500 \mathrm{~kg}$ natural uranium target assembly QUINTA irradiated by deuterons with energies from 1 to 8 $\mathrm{GeV}$ at JINR NUCLOTRON // XXI International Baldin Seminar on High Energy Physics Problems "Relativistic Nuclear Physics and Quantum Chromodynamics". 10-15 Sept. 2012, JIPR Proceedings of Science.

6. V.A. Voronko et al. Estimation of the beam power gain for deep-subcritical uranium assembly Quinta under relativistic proton, deuteron and carbon nuclei irradiation // Problems of Atomic Science and Technology. Series "Nuclear Physics Investigations". 2018, №3, p. 183-187.

7. T.T. Böhlen. The FLUKA Code: Developments and Challenges for High Energy and Medical Applications / T.T. Böhlen, F. Cerutti, M.P.W. Chin, A. Fassò, A. Ferrari, P.G. Ortega, A. Mairani, P.R. Sala, G. Smirnov and V. Vlachoudis, Nuclear Data Sheets. 2014, 120, p. 211-214.

8. A. Ferrari. FLUKA: a multi-particle transport code / A. Ferrari, P.R. Sala, A. Fasso', and J. Ranft, 
CERN-2005-10 (2005), INFN/TC_05/11, SLAC-R773.

9. V.S. Pronskich et al. Energy Production Demonstrator and Material Testing Station optimization for
Megawatt proton beams // Annals of Nuclear Energy. 2017, v. 109, p. 692-697.

Article received 08.10.2019

\section{НЕЙТРОННО-ФИЗИЧЕСКИЕ ХАРАКТЕРИСТИКИ СИСТЕМЫ КВАЗИБЕСКОНЕЧНАЯ УРАНОВАЯ МИШЕНЬ-УСКОРИТЕЛЬ. МОДЕЛИРОВАНИЕ МЕТОДОМ МОНТЕ-КАРЛО}

О.В. Бухал, К.В. Гусак, И.В. Жук, В.А. Воронко, В.В. Сотников, А.А. Жадан, А.А. Балдин,

\section{С.И. Тютюнников}

Проведено моделирование облучения квазибесконечной урановой мишени потоком протонов и дейтронов с энергией 1 ГэВ с использованием компьютерного кода FLUKA. В результате моделирования получены нейтронные спектры и потоки нейтронов в объеме сборки. Определены скорости реакций ${ }^{235} \mathrm{U}(\mathrm{n}, \mathrm{f}),{ }^{238} \mathrm{U}(\mathrm{n}, \mathrm{f})$, ${ }^{238} \mathrm{U}(\mathrm{n}, \mathrm{g})$ в мишени. Рассчитан коэффициент усиления мощности налетающего пучка частиц.

\section{НЕЙТРОННО-ФІЗИЧНІ ХАРАКТЕРИСТИКИ СИСТЕМИ КВАЗІНЕСКІНЧЕНА УРАНОВА МІШЕНЬ-ПРИСКОРЮВАЧ. МОДЕЛЮВАННЯ МЕТОДОМ МОНТЕ-КАРЛО}

О.В. Бухал, К.В. Гусак, І.В. Жук, В.О. Воронко, В.В. Сотніков, А.О. Жадан, О.О. Балдін, С.І. Тютюнников

Проведено моделювання опромінення квазінескінченої уранової мішені потоком протонів і дейтронів 3 енергією 1 ГеВ з використанням комп'ютерного коду FLUKA. В результаті моделювання отримані нейтронні спектри і потоки нейтронів в обсязі збірки. Визначено швидкості реакцій ${ }^{235} \mathrm{U}(\mathrm{n}, \mathrm{f}),{ }^{238} \mathrm{U}(\mathrm{n}, \mathrm{f}),{ }^{238} \mathrm{U}(\mathrm{n}, \mathrm{g})$ у мішені. Розрахований коефіцієнт посилення потужності налітаючого пучка частинок. 